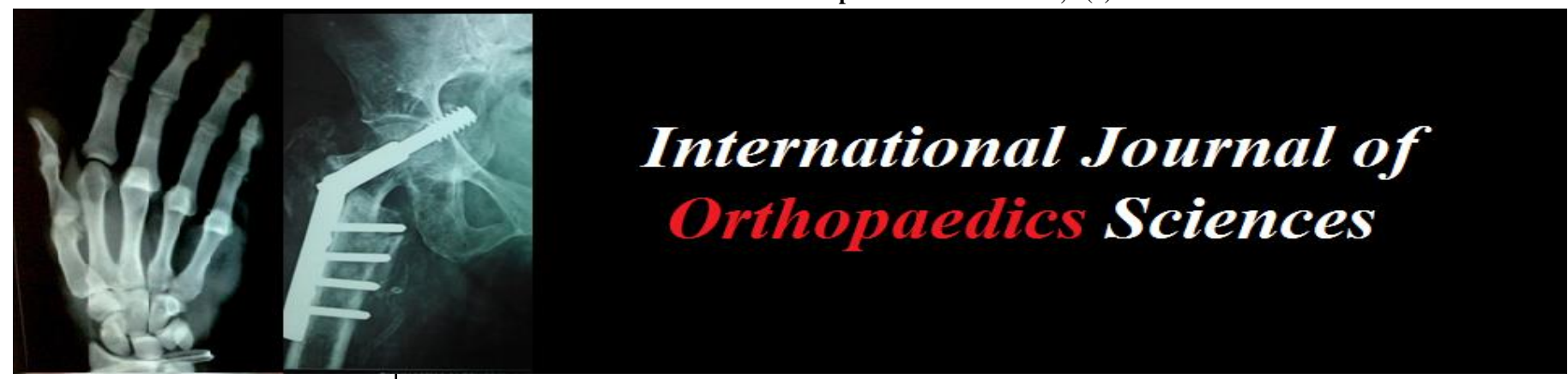

ISSN: $2395-1958$

IJOS 2018; 4(4): 123-128

(C) 2018 IJOS

www.orthopaper.com

Received: 04-08-2018

Accepted: 08-09-2018

Dr. Loya Lavakumar S

Associate Professor, Department of Orthopaedics, M R Medical

College, Kalaburagi, Karnataka, India

Dr. Madhusudhan R

Post graduate, Department of Orthopaedics, M R Medical College, Kalaburagi, Karnataka, India
Correspondence

Dr. Loya Lavakumar S

Associate Professor, Department of Orthopaedics, M R Medical College, Kalaburagi, Karnataka, India

\section{A prospective study for definitive diagnosis of various arthropathies by synovial fluid analysis and percutaneous needle biopsy of synovium}

\section{Dr. Loya Lavakumar S and Dr. Madhusudhan R}

DOI: https://doi.org/10.22271/ortho.2018.v4.i4c.22

\section{Abstract}

Objectives: To evolve a diagnostic pattern of synovial fluid analysis, thus determining the usefulness of routine synovial fluid analysis as a simple diagnostic aid in various forms of arthritis.

Background: Synovial fluid analysis is a simple, inexpensive investigation, whereby, based on simple laboratory tests and the physical characteristics of the synovial fluid, definitive diagnosis of various arthritis could be arrived at. Synovial fluid aspiration is a simple OPD procedure. It does not need much expertise. It could be performed in all hospitals including the primary health centre.

Methods: 50 patients with joint effusion attending the orthopaedic outpatient department of our hospital, were selected at random. They were examined clinically, subjected to routine laboratory investigations, radiology and then synovial fluid aspiration was done under aseptic precautions and sent to biochemistry, pathology and microbiology departments for synovial fluid analysis. Doubtful cases based on synovial fluid analysis reports, were subjected to histopathological examination.

Results: Out of the 50 cases, 13 cases were diagnosed as osteoarthritis, 12 as traumatic arthritis/ haemarthrosis, 6 patients were diagnosed as tuberculous arthritis, 5 as septic arthritis and 5 patients as rheumatoid arthritis. One case each was diagnosed as gouty arthritis and neuropathic joint effusion. 7 cases were diagnosed as chronic non-specific synovitis as no definitive diagnosis could be arrived at, after interpreting the synovial fluid analysis findings and histopathological examination.

Interpretation and Conclusion: Synovial fluid analysis is a satisfactory procedure in terms of both diagnosis as well as patient's compliance point of view, especially in a patient of rural area and lower socio-economic strata. Diagnosis of various arthropathies can be obtained and obtained early in a significant number of cases. The technique can eliminate unnecessary treatment and possibly, the need for an arthrotomy.

Keywords: synovial fluid; osteoarthritis; rheumatoid arthritis; tuberculous arthritis; septic arthritis; gouty arthritis; neuropathic joint effusion; traumatic arthritis/ haemarthrosis; chronic non-specific arthritis

\section{Introduction}

Arthritis is a major health problem, where, though the mortality is very less, morbidity is very high. It is one of the oldest and yet the most neglected disease. The earliest known example is the evidence of arthritis being found in the skeleton of a large swimming reptile, which lived about 1,000,000,000 years ago with multiple arthritis in vertebral joints, now being preserved in the museum of Kansas University.

It has been emphasized that synovial fluid examination mirrors the pathology of joint disease, in much the same way as urine analysis in genito-urinary tract diseases. Since the underlying synovial tissue reaction is often reflected in the joint fluid, its analysis may provide much information about the disorders at this primary site of activity itself. Careful examination adds to the accuracy of diagnosis and at times, proves to be the only means of establishing it correctly.

The following are the aims and objectives of our study

1. To study synovial fluid analysis in the form of its physical nature, cytology, biochemical changes and microscopic appearance.

2. To aid in the definitive diagnosis of septic arthritis, tubercular arthritis, syphilitic arthritis, 
rheumatoid arthritis, osteoarthritis, gouty arthritis, neuropathic joint effusion, pigmented villo nodular synovitis, haemophilic arthritis, etc. and thus in its treatment.

3. To diagnose the cause of swelling and pain in the joints.

\section{Methods}

The present study comprises of fifty cases of joint effusions which were investigated and treated at Basaveshwara Teaching \& General Hospital, attached to Mahadevappa Rampure Medical College, kalaburagi who attended the Orthopaedic Outpatient Department during the study from September 2016 to August 2018. Cases were selected at random who had joint symptoms and effusions.

\section{Procedure:}

The skin over the joint was cleansed with betadine (povidine iodine) solution and spirit and draped with sterile towel. The skin over the area of puncture, subcutaneous tissue, deep fascia and capsule were infiltrated with $2 \mathrm{ml}$ of $2 \%$ xylocaine. A large bore needle (No. 16 to 18 gauge) was used for aspiration. The fluid was aspirated with a $10 \mathrm{ml}$ syringe.

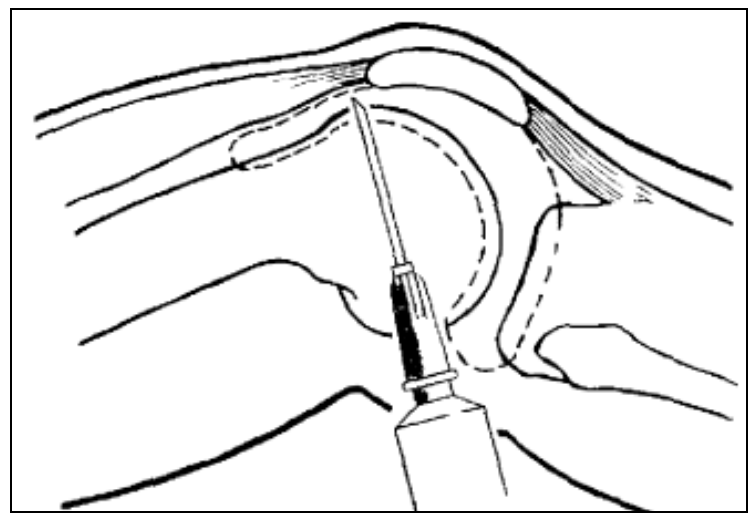

Fig 1: Showing the entry point into supra patella pouch

The fluid thus aspirated, was collected and portioned into four separate parts

1. Plain bulb for physical examination.

2. Double oxalate bulb $-3 \mathrm{ml}$ of fluid for cytological study.

3. Plain bulb for biochemical study

4. Sterile bulb for culture and sensitivity.

Gross Appearance of Synovial Fluid: Synovial fluid was assessed for Volume, colour, clarity, viscosity and clot formation

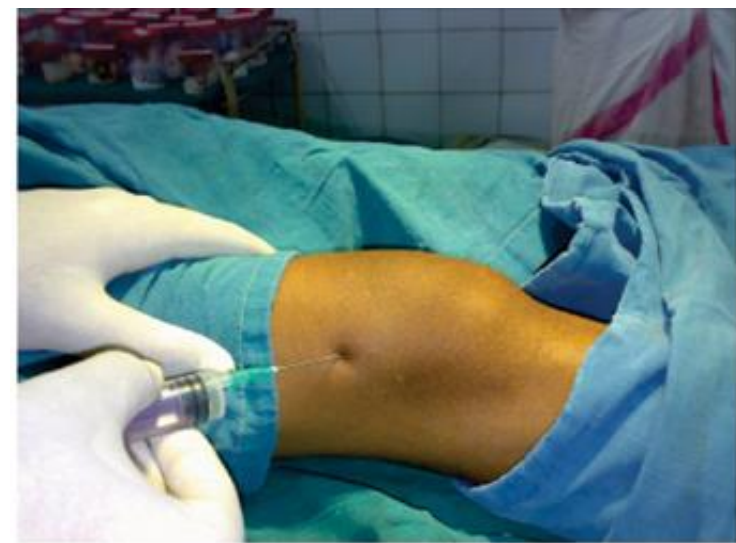

Method of Aspiration of Knee Joint

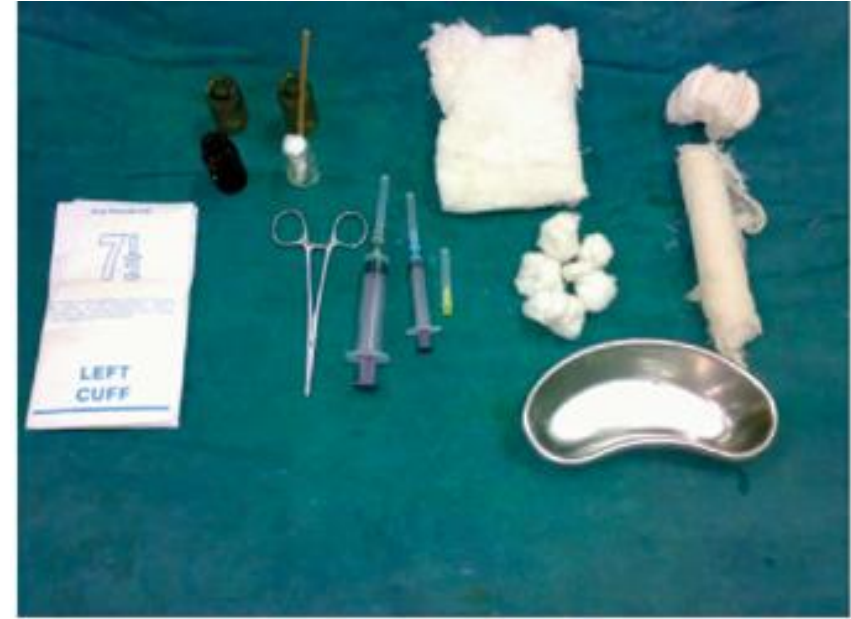

Arthrocentesis Tray

The following procedures were done in the Department of Pathology:

Microscopic Examination

a) Unstained Preparation

b) Stained preparation for cytological examination:

i) Total leukocyte count :Differential count of leukocytes: Presence of Histocytes, synovial cells and cytoplasmic inclusion granules:

The following procedures were done in the Department of Microbiology

\section{Bacteriological examination}

Synovial fluids after aspiration were sent for culture. In this series, blood agar was used as a culture media for all nontuberculous patients. In cases of tuberculous patient, culture was plated on Lowenstein-Jensen media.

The following procedures were done in the Department of Biochemistry:

\section{Biochemical Examination}

a) Sugar:

b) Protein: Protein content of synovial fluid was estimated by Biuret method as grams per $100 \mathrm{cc}$ of fluid.

c) Mucin clot test (Ropes Test)

\section{Biopsy}

It was performed for histopathological examination in doubtful cases using $10 \%$ formalin as preservative.

\section{Results}

All the patients were examined with routine laboratory and radiological examination were done in all cases. Synovial biopsy was done to confirm the diagnosis in tuberculous arthritis, rheumatoid arthritis and chronic non-specific arthritis. Synovial fluid was aspirated from the affected joints (47 knee, 2 elbow and 1 metatarsophalangeal joint) and analysis was done.

Final diagnosis in the present study, by clinical examination, other conventional investigation, synovial fluid analysis and synovial biopsy of different arthritides are categorized into the following arthritides.

In this series, the number of patients suffering from different arthritides is shown in table-1. 
Table 1: Distribution of different arthritides

\begin{tabular}{|c|c|c|}
\hline Type of arthritis & Number & Percentage \\
\hline Osteoarthritis & 13 & 26.00 \\
\hline Traumatic arthritis/ haemarthrosis & 12 & 24.00 \\
\hline Chronic non-specific arthritis & 7 & 14.00 \\
\hline Tuberculous arthritis & 6 & 12.00 \\
\hline Rheumatoid arthritis & 5 & 10.00 \\
\hline Septic arthritis & 5 & 10.00 \\
\hline Gouty arthritis & 1 & 2.00 \\
\hline Neuropathic joint effusion & 1 & 2.00 \\
\hline Total & 50 & 100.00 \\
\hline
\end{tabular}

\section{Distribution of different arthritides}

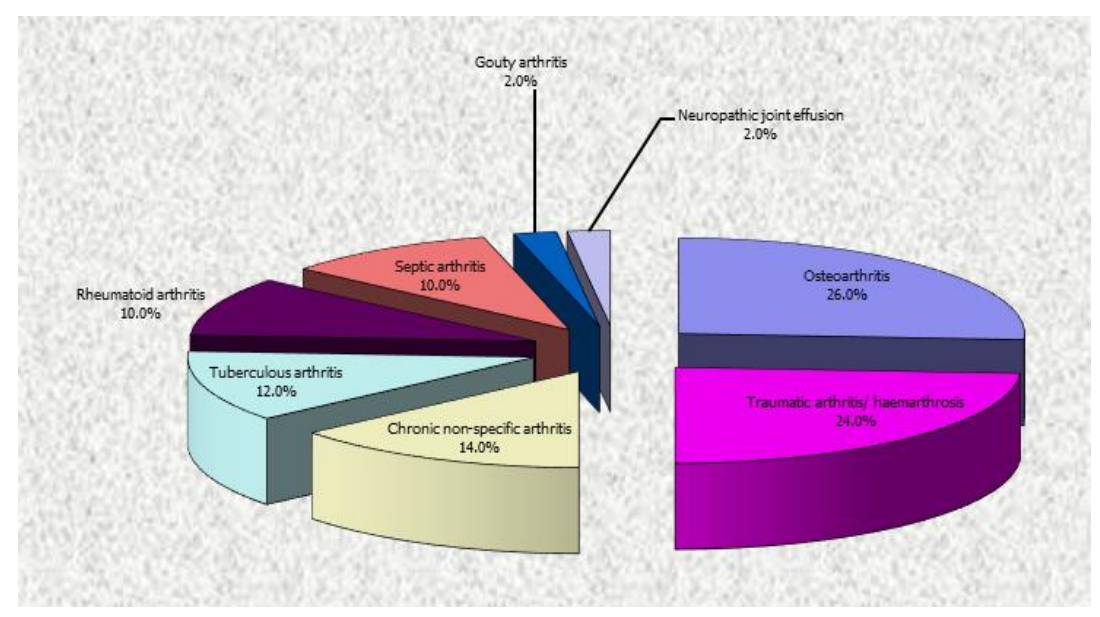

Table 2: Age distribution of various types of arthritis

\begin{tabular}{|c|c|c|c|c|c|c|c|}
\hline \multirow{2}{*}{ Types of arthritis } & \multirow{2}{*}{ Total No. of cases } & \multicolumn{5}{|c|}{ Age group in years } \\
\cline { 3 - 8 } & & $\mathbf{1 1 - 2 0}$ & $\mathbf{2 1 - 3 0}$ & $\mathbf{3 1 - 4 0}$ & $\mathbf{4 1 - 5 0}$ & $\mathbf{5 1 - 6 0}$ & $\mathbf{7 0}$ \\
\hline Osteoarthritis & 13 & -- & -- & -- & 3 & 6 & 4 \\
\hline Traumatic arthritis/ haemarthrosis & 12 & 1 & 4 & 2 & 4 & 1 & -- \\
\hline Chronic non-specific arthritis & 7 & 1 & 3 & 3 & -- & -- & -- \\
\hline Tuberculous arthritis & 6 & 3 & 1 & 2 & -- & -- & -- \\
\hline Rheumatoid arthritis & 5 & -- & 4 & 1 & -- & -- & -- \\
\hline Septic arthritis & 5 & 2 & 1 & -- & 1 & 1 & -- \\
\hline Gouty arthritis & 1 & -- & -- & -- & 1 & -- & -- \\
\hline Neuropathic joint effusion & 1 & 1 & -- & -- & -- & -- & -- \\
\hline
\end{tabular}

\section{Age distribution of various types of arthritis}

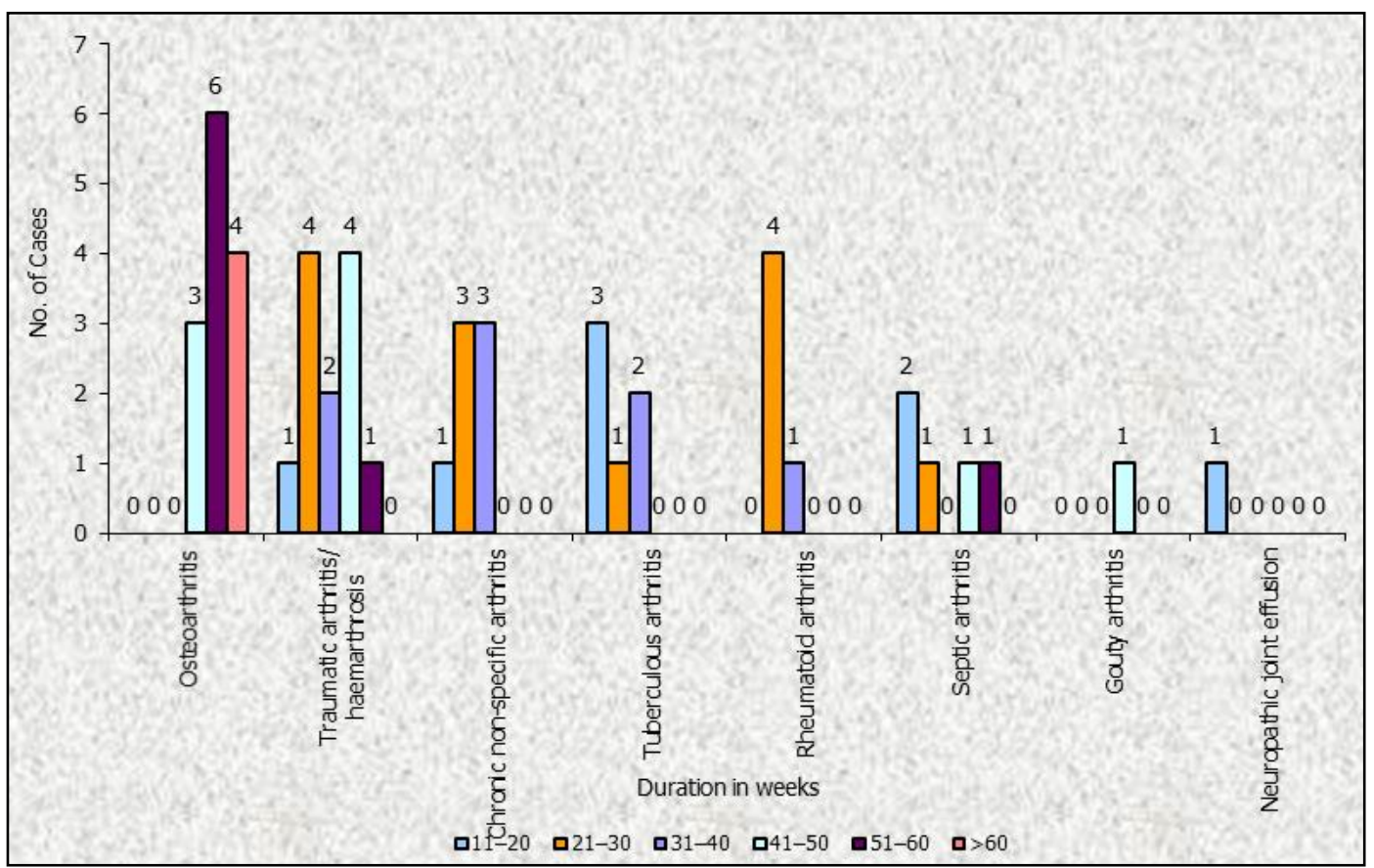


Table 3: Sex distribution in various arthritides

\begin{tabular}{|c|c|c|c|}
\hline Type of arthritis & Total No. of cases & No. of male & No. of female \\
\hline Osteoarthritis & 13 & 7 & 6 \\
\hline Traumatic arthritis/ haemarthrosis & 12 & 11 & 1 \\
\hline Chronic non-specific arthritis & 7 & 5 & 2 \\
\hline Tuberculous arthritis & 6 & 4 & 2 \\
\hline Rheumatoid arthritis & 5 & 2 & 3 \\
\hline Septic arthritis & 5 & 4 & 1 \\
\hline Gouty arthritis & 1 & 1 & -- \\
\hline Neuropathic joint effusion & 1 & -- & 1 \\
\hline
\end{tabular}

Table 4: Showing physical properties of synovial fluid in normal and diseased joints.

\begin{tabular}{|c|c|c|c|c|c|c|}
\hline no & Disease & Volume in ml & Appearance color/clarity & Mucin clot test & Viscosity & Fibrin clot \\
\hline & normal & 3.5 & Straw/clear & Good & Good & - \\
\hline 1 & Osteoarthritis & Variable & Pale /yellow & Good & normal & - \\
\hline 2 & Traumatic arthritis/ haemarthrosis & Variable & Haemorrhagic/xanthochromic & Fair to good & decreased & - \\
\hline 3 & Chronic non-specific arthritis & Moderately increased & Straw/yellow & Fair to good & decreased & $+/-$ \\
\hline 4 & Tuberculous arthritis & Moderately increased & Yellow & poor & decreased & + \\
\hline 5 & Rheumatoid arthritis & Variablr & Yellowish green & poor & decreased & + \\
\hline 6 & Septic arthritis & Abundant & Grey & poor & decreased & + \\
\hline 7 & Gouty arthritis & Scanty & Yellow & poor & decreased & - \\
\hline 8 & Neuropathic joint effusion & Scanty & Yellow & fair & Normal & - \\
\hline
\end{tabular}

Table 5: Showing cytological appearance of normal and diseased joints

\begin{tabular}{|c|c|c|c|}
\hline No & Disease & Total WBC count/mm & Predominant cell type \\
\hline & Normal synovial fluid & $<\mathbf{2 0 0}$ & Mixed cell with poly, Lympho mono poly less 12 (25\%) \\
\hline 1 & Osteoarthritis & $500-1000$ & Variable from polymorphs to lymphocytes \\
\hline 2 & Traumatic arthritis/ haemarthrosis & $1000-5000$ & Predominantly mononuclear cells \\
\hline 3 & Chronic non specific arthritis & $<1000$ & Variable from polymorphs to lymphocytes \\
\hline 4 & Tubercular arthritis & $1000-50000$ & Lymphocytes 60 to $80 \%$ with monocytes \\
\hline 5 & Rheumatoid arthritis & $2000-40000$ & Polymorphs 65 to $80 \%$ \\
\hline 6 & Septic arthritis & $>5000$ & Polymorphs 80 to $95 \%$ \\
\hline 7 & Gouty arthritis & $2000-15000$ & Polymorphs 60 to $80 \%$ \\
\hline 8 & Neuropathic joint effusion & $<1000$ & Mono nuclear cells \\
\hline
\end{tabular}

Table 6: Showing cytological appearance of normal and diseased joints

\begin{tabular}{|c|c|c|c|}
\hline No & Disease & Total WBC count/mm & Predominant cell type \\
\hline & Normal synovial fluid & $<200$ & Mixed cell with poly, Lympho mono poly less 12 (25\%) \\
\hline 1 & Osteoarthritis & $500-1000$ & Variable from polymorphs to lymphocytes \\
\hline 2 & Traumatic arthritis/ haemarthrosis & $1000-5000$ & Predominantly mononuclear cells \\
\hline 3 & Chronic non specific arthritis & $<1000$ & Variable from polymorphs to lymphocytes \\
\hline 4 & Tubercular arthritis & $1000-50000$ & Lymphocytes 60 to 80\% with monocytes \\
\hline 5 & Rheumatoid arthritis & $2000-40000$ & Polymorphs 65 to $80 \%$ \\
\hline 6 & Septic arthritis & $>5000$ & Polymorphs 80 to $95 \%$ \\
\hline 7 & Gouty arthritis & $2000-15000$ & Polymorphs 60 to $80 \%$ \\
\hline 8 & Neuropathic joint effusion & $<1000$ & Mono nuclear cells \\
\hline
\end{tabular}

Table 7: Showing protein content of synovial fluid and blood - synovial fluid glucose difference in various joint diseases

\begin{tabular}{|c|c|c|c|}
\hline No & Disease condition & Protein gm \% & Blood - synovial fluid glucose level difference mg\% \\
\hline & Normal & $1.5-2.5$ & $<10$ \\
\hline 1 & Osteoarthritis & $2.0-4.0$ & $<20$ \\
\hline 2 & Traumatic arthritis/haemarthrosis & $3.1-5.0$ & $<20$ \\
\hline 3 & Chronic non specificarthritis & $2.0-4.0$ & $>10-<16$ \\
\hline 4 & Tubercular arthritis & $4.1-6.0$ & $>20-<35$ \\
\hline 5 & Rheumatoid arthitis & $5.1->6.0$ & $>20-<30$ \\
\hline 6 & Septic arthritis & $4.1-6.0$ & $>50$ \\
\hline 7 & Gouty arthritis & $3.1-4.0$ & $<25$ \\
\hline 8 & Neuropathic joint effusion & $3.1-4.0$ & $<20$ \\
\hline
\end{tabular}

\section{Bacterial culture}

Culture was positive in all the 5 cases of septic arthritis. Staphylococcus aureus was the organism isolated in 4 cases and streptococcus haemolyticus in the other case. Culture was negative in all the other cases. Tuberculous bacilli was not isolated in the Ziehl-Neelsen stained smear of the fluid in a single case of tuberculous arthritis.

\section{Biopsy}

In the tuberculous arthritis and rheumatoid arthritis cases, the diagnosis was confirmed by synovial biopsy and histopathological examination. The 7 cases of chronic nonspecific arthritis were also subjected to biopsy to conform the diagnosis. 

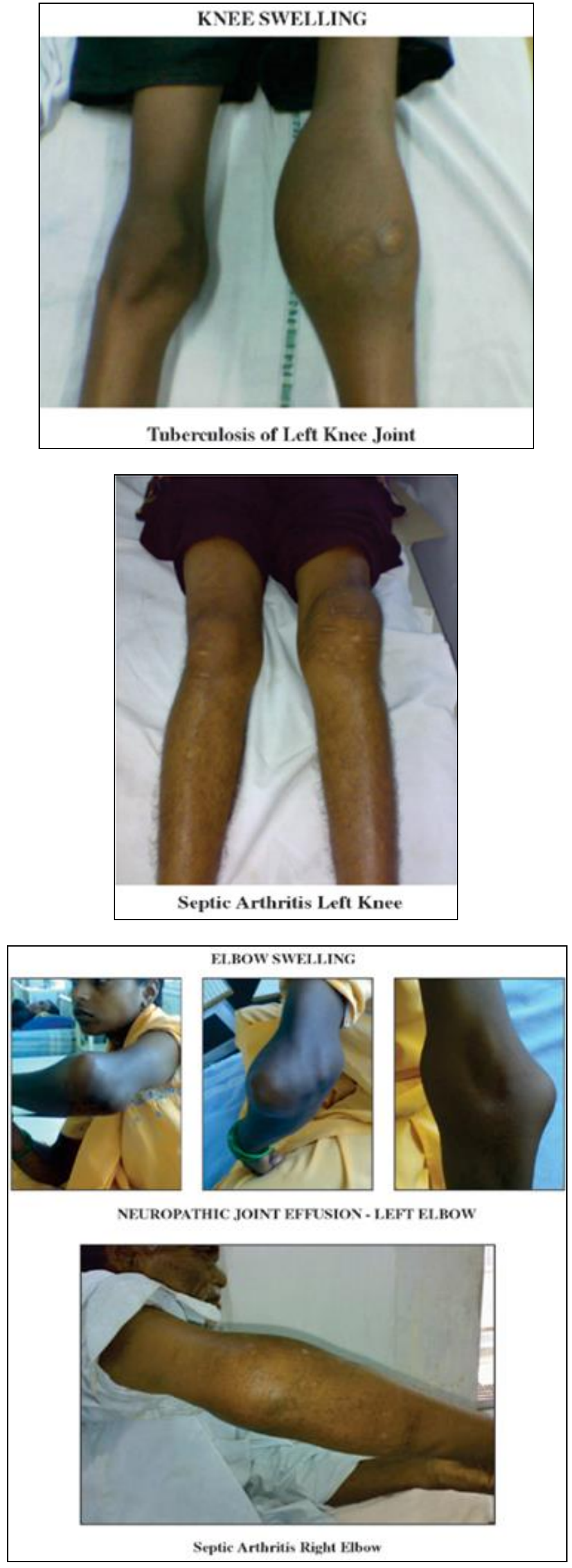

\section{Discussion}

Affection of the joints, monoarticular or polyarticular by various diseases is a common orthopedic problem. On the basis of clinical examination with conventional radiological and laboratory aids, the diagnosis often can be reasonably made. These findings are sometimes equivocal and therefore necessity of tissue diagnosis arises. In the present study, it is evident that synovial fluid analysis is a simple investigation and has a contributory role in the diagnosis of various arthropathies. In the present scenario, advanced investigations like CT, MRI, polymerase chain reaction and immunocytopathology study were not used, which are frequently asked for by an orthopaedician to arrive at a diagnosis. These investigations are not available at all centers especially in rural areas.

Closed needle biopsy is a simple outpatient procedure without complications that aids in establishing the diagnosis after clinical and radiological correlation ${ }^{[18]}$. Careful review of literature would reveal that the importance of this simple procedure as an aid to diagnosis of joint diseases has been stressed by various authors from time to time. Involvement of knee has been found commonest in joint disease both by present study and also by previous workers. Monoarticular involvement of knee has been found more common than polyarticular affection both in present study $60(65.78 \%)$ and by previous workers ${ }^{[15]}$.

Septic arthritis is a rheumatological emergency and delay in diagnosis and treatment can lead to irreversible joint damage, significant morbidity and even mortality ${ }^{[16]}$. The two patients with proven septic arthritis in this study were both picked up on gross analysis, and management was initiated even before Gram stain results were made available.

Joint effusions present as a diagnostic challenge to physicians and need careful evaluation and interpretation of both clinical and laboratory findings to make accurate diagnosis, initiate appropriate management and avoid unnecessary hospital stay [12]. The standardised method of documenting gross analysis of synovial fluid was found to be helpful by both junior and senior medical staff. We recommend that it is used in daily practice. This information could be incorporated on to laboratory request forms and be reported by the laboratory staff at the time of analysis ${ }^{[17]}$ This would ensure that this test is performed reliably and is consistently available to clinicians making treatment decisions. Where the fluid is noninflammatory on gross analysis, a synovial fluid white cell count cannot be recommended. The place of a white cell count in the management of patients with potential inflammatory arthritis cannot be determined from this study. However, a white cell count in the inflammatory range cannot reliably be used to exclude septic arthritis. Until further work is done to standardise laboratory cell count methodology, the use of a standardised gross synovial fluid analysis should be performed in preference to a laboratory white cell count ${ }^{[23]}$.

Tubercular and rheumatoid were seen in maximum numbers and next common group chronic nonspecific synovitis. Septic arthritis, osteo arthritis and traumatic arthritis formed the third common group. Rheumatoid lesion and osteoarthrosis were seen largely a polyarticular affection, while tubercular arthritis, chronic nonspecific synovitis, septic arthritis, gout and traumatic arthritis were predominantly single joint involvement. This observation noticed by present study almost tallied with study of previous workers. On the basis of synovial fluid evaluation (physical, biochemical and cytological examination) and according to severity of inflammation, the various types of arthritis are grouped.

In cases where the clinical radiological, synovial fluid findings and even the histologic study by closed needle biopsy were inconclusive for any definite disease and were 
labeled as chronic nonspecific synovitis. These cases were proved chronic nonspecific synovitis also by open biopsy [24] Hence, synovial fluid analysis has proved to be a simple investigation, available at all centres, rural or urban, having a definite contributory role in the diagnosis of various arthropathies.

\section{Conclusion}

In the present study, it was attempted to evaluate synovial fluid analysis as a modality of investigation in the various arthritides. On analyzing the results it was found that: The evaluation of synovial fluid and synovial biopsy should be an important part of investigative procedure in patients presenting with joint effusion. The nature of underlying synovial tissue reaction is often reflected in synovial fluid and synovial tissue histologic study which may give conclusive diagnosis where clinical diagnosis is equivocal.

Thus, synovial fluid analysis has a definite contributory role in diagnosing various arthropathies. When we compared with clinical examination and other routine investigation including radiography, synovial fluid analysis has improved the accuracy of diagnosis.

Hence, a simple investigation like synovial fluid analysis should be done by orthopaedic surgeon in patients with joint effusion. This will obviate the need of sophisticated investigations like CT, MRI, polymerase chain reaction (PCR), immunocytology study, etc., thereby reducing the cost factor.

\section{Conflicts of interest}

There are no conflicts of interest, none declared

\section{References}

1. Lohmander LS, Hoerrner LA, Lark MN. Metalloproteinases, tissue inhibitor and proteoglacan fragments in knee joint fluid in human osteoarthritis. Arthr Rheum. 1993; 36(2):181-189.

2. Bohndorf Klaus, ImhofHerwing, Pope TL Jr. Musculoskeletal imaging - A concise multimodality approach. Thieme, 1998, 292-93.

3. Standring Susan. Gray's Anatomy. The Anatomical Basis of Clinical Practice. Elsevier Churchill Livingstone, $39^{\text {th }}$ Edition, 107-110.

4. Larsen William J. Human Embryology. Churchill Livingstone. 1997, 319-320.

5. Hollander JL. Arthritis and Allied Condition. Lea \& Febiger, Philadelphia, $5^{\text {th }}$ Ed., 1954, 49.

6. Bauer W, Ropes MW, Waine, Hans with Physiol Rev. 1940; 20:272.

7. Turek Samuel L. Orthopaedic Principles and Their Application, $4^{\text {th }}$ ed., 2000, 382-383.

8. Cajori FA, Pemberton R. The chemical composition of synovial fluid in cases of joint effusion. J Biol Chem. 1928; 76:471-80.

9. Snell Richard S. Clinical anatomy for medical students. $7^{\text {th }}$ Ed., 2004, 15-18.

10. Jessar RA. The study of synovial fluid. Chapter-6. In: Arthritis and Allied Conditions. Hollander JL and McCarty DJ, $8^{\text {th }}$ Ed., Philadelphia, Lea \& Febiger.

11. Curtis PH Jr. Changes produced in the synovial membrane and synovial fluid by disease. Journal of Bone \& Joint Surgery, 1964; 46A:873-888.

12. Hollander JL, Reginoto A, Torralba TP. Examination of synovial fluid as a diagnostic aid in arthritis. Med Clin North America. 1966; 50:1281-1293.
13. Wolf AW, Benson DR, Shoji H, Riggins RS. Current concepts in synovial fluid analysis. Clin Ortho \& Related Res. 1978; 134:261-265.

14. Delbarre F, Kahan A, Amor B, Krassinine G. Le ragonyte synovial son interetpour le diagnostic des maladies rhymatismales. Press e Med, 1964; 72:2129-2132.

15. Hamerman D, Sandoson T, Schubert M. Biochemical events in joint disease. J Chron Dis. 1963; 16: 835-852.

16. Duthie RB and Gentley George. Mercer's Orthopaedic Surgery, $9^{\text {th }}$ Ed., 2003, 17-19.

17. Sakhuja AC, Singh SN, Chaturvedi SN, Bajpai J. Synovial fluid analysis and synovial biopsy in various types of arthritides. Indian J of Ortho. 1981; 15(2):15761.

18. Lowell MH, Durban NC. The routine examination of synovial fluid. South Med J. 1964; 57:1396-1400.

19. Garg ML, Kumar R, Chugh TD, Maini PS. Value of synovial fluid analysis as a diagnostic tool in arthritis. Ind J Med Res. 1972; 60:233-245.

20. Austin FK, Calkings E. Serial studies of synovial fluid in evaluating intra-articular agents. Ann Rheumat Dis. $1955 ; 14: 283-287$.

21. Astorga G, Bollet AJ. Diagnostic specificity and possible pathogenetic significance of inclusions in synovial leukocyte. Arthritis \& Rheumatism. 1965; 8:511-523.

22. Rawson AJ, Abelson NM, Hollander JL. Studies on the pathogenesis of rheumatoid joint inflammation. II Intracytoplasmic particulate complexes in rheumatoid synovial fluids. Ann Int Med. 1965; 62:271-280.

23. Ganesh Kumar Reddy Mundla, Ram Prasad Rallapalli. a prospective study for diagnosing joint diseases by synovial fluid analysis and percutaneous needle biopsy of synovium Int J Res Orthop 2017/ issn.2455-4510.

24. Gross synovial fluid analysis in the differential diagnosis of joint effusion S Abdullah, S A Young-Min, S J Hudson, C A Kelly, C R Heycock, J D Hamilton. uk Accepted 11 December 2006 Published Online First 26 January 2007...................... J Clin Pathol. 2007; 60:1144-1147. doi: 10.1136/jcp.2006.043950. 